\title{
Association between the Diet Quality Index Adapted for Pregnant Women (IQDAG) and excess maternal body weight
}

Lívia Castro Crivellenti 1

https://orcid.org/0000-0002-9038-0996

Daniela Cristina Candelas Zuccolotto 2

https://orcid.org/0000-0001-6472-4882

Daniela Saes Sartorelli 3

https://orcid.org/0000-0003-2028-3274

\begin{abstract}
1,2 Pós-Graduação em Saúde Pública. Faculdade de Medicina de Ribeirão Preto. Universidade de São Paulo. Av. Bandeirantes, 3900. Vila Monte Alegre. Ribeirão Preto, SP, Brasil. CEP: 14.049-900. E-mail: iacrivelenti@gmail.com
\end{abstract}

3 Departamento de Medicina Social. Faculdade de Medicina de Ribeirão Preto. Universidade de São Paulo. Ribeirão Preto, SP, Brasil.

\begin{abstract}
Objectives: to investigate the relationship between the Diet Quality Index Adapted for Pregnant Women (IQDAG) and excess maternal body weight.

Methods: a cross-sectional study was conducted with 754 adult pregnant women, in Ribeirão Preto, São Paulo, between 2011 and 2012. The criteria proposed by Atalah were used to classify the body mass index (BMI). Adjusted multinomial logistic regression models were employed to investigate the relationship between the IQDAG and being overweight and obese, estimating the odds ratio (OR) and the 95\% confidence interval (CI95\%).

Results: the mean (SD) age of women was 28 (5) years, $33.4 \%$ were overweight and $25.6 \%$ obese. The pregnant women with higher scores in the IQDAG were less likely to be overweight $[O R=0.56(C 195 \%=0.37-0.85)]$ or obese [0.43 (0.26-0.71)]; those with higher scores in the "Fiber" [0.51 (0.33; 0.78)] and "Iron" [0.62 (0.40-0.96)] components were less likely to be overweight. However, women with higher scores in the percentage of energy from ultra-processed foods were more likely to be overweight [1.72 (1.10-2.94)] or obese [5.24 (2.80-9.80)], when compared to women with lower scores.

Conclusions: poorer quality maternal diets were observed among the women who were overweight and obese during pregnancy.

Key words Pregnant women, Food consumption, Overweight, Obesity
\end{abstract}




\section{Introduction}

The high prevalence of overweight and obesity during pregnancy is a relevant public health problem, predicting adverse health outcomes for the mother and child binomial in both short and long term. ${ }^{1}$ In addition to the immediate implications for pregnant women, excess maternal body weight during gestation is considered a determinant of the health of the fetus, which may be at risk of developing obesity, cardiovascular disease and allergies in childhood and adult life. ${ }^{2}$

Evidence suggests that diet is an important determinant of excess pre-gestational body weight and excessive weight gain. ${ }^{3,4}$ Diet quality indexes (DQIs) are tools that allow the evaluation and monitoring of dietary adherence to nutritional recommendations, based on pre-determined dietary components (nutrients and foods), 5 making it possible to verify relationships between diet and health outcomes. 3 Accordingly, different international investigations have been conducted to evaluate the relationship between diet quality in pregnancy and weight indicators. 6,7

Studies indicate an inverse relationship between the quality of maternal diet and the body mass index (BMI) in pregnancy. Mariscal-Arcas et al. 6 observed that greater adherence to the Mediterranean Diet Score for pregnancy (MDS-P) was associated with a lower mean BMI $\left(\mathrm{kg} / \mathrm{m}^{2}\right)$ at the beginning of pregnancy and a lower mean weight $(\mathrm{kg})$ at the end of gestation. Among 955 women monitored in the cohort study Growing Up in Singapore Towards Healthy Outcomes (GUSTO), in the years 2009 to 2010 , it was verified that pregnant women with greater adherence to the Healthy Eating Index for Pregnant Women in Singapore (HEI-SGP) presented the lowest mean BMI at the $26^{\text {th }}$ week of gestation. ${ }^{7}$

In a cross-sectional study conducted in Greece with 100 pregnant women, between 2007 and 2008, better dietary quality was observed, according to the Healthy Eating Index 2005 (HEI-2005), among low weight and eutrophic women when compared with those presenting obesity. ${ }^{8}$

In the Brazilian context, no epidemiological studies that investigate the relationship between dietary indexes in pregnancy and excess maternal body weight were found in the literature. The Index of Quality of the Adapted Diet for Pregnant Women (Índice de Qualidade da Dieta Adaptado para Gestantes - IQDAG), which was developed for pregnant Brazilian women, ${ }^{9}$ was precursory when incorporated recommendations of the current food guide 10 regarding the moderation of consumption of ultra-processed foods, given the evidence of their relationship with the occurrence of obesity and noncommunicable diseases. ${ }^{11}$

Considering the adverse effects of excess body weight on the health of the mother-child binomial, as well as the relevant role of diet as a determinant of these outcomes, the aim of the present study was to investigate the relationship between the IQDAG and overweight and obesity in pregnancy, to test the hypothesis that a better quality diet in pregnancy is inversely associated with excess maternal body weight.

\section{Methods}

Data from the present study were obtained from a cross-sectional study conducted with adult pregnant women attended in the Health Unic System (Sistema Unico de Saúde - SUS) of the municipality of Ribeirão Preto, São Paulo, between 2011 and 2012, which aimed to investigate the relationship between the estimation of dietary nutrients of pregnant women and gestational diabetes mellitus (GDM), as described in detail by Barbieri et al. 12

The inclusion criteria of the study were: age $\geq 20$ years, pre-gestational $\mathrm{BMI} \geq 20 \mathrm{~kg} / \mathrm{m}^{2}$ and gestational age (GA) from the 24th week of gestation. Pregnant women with pre-gestational $\mathrm{BMI} \geq 20$ $\mathrm{kg} / \mathrm{m}^{2}$ were included in order to select women with a greater chance of GDM. Exclusion criteria were: women who reported having type 1 diabetes mellitus or type 2 diabetes mellitus, using glucose-modifying medications (such as glucocorticoids), having chronic kidney disease, acquired immunodeficiency syndrome (AIDS) or cancer and women that did not provide complete data.

The sample size calculation was based on the primary outcome of the cross-sectional study, gestational diabetes. Considering a prevalence of $20 \%$ of GDM among adult women attended in the SUS, with an acceptable margin of error of $5 \%$, a sample of 512 pregnant women was necessary.

The present study was approved by the Research Ethics Committee of the School Health Center of Ribeirão Preto Medical School, University of São Paulo, CEP/CSE-FMRP-USP-034/2014 (CAAE: 28178514.3.0000.5414). All the pregnant women that agreed to participate in the study signed the consent form.

The pregnant women underwent an anthropometric evaluation at the time of the interview. Weight $(\mathrm{kg})$ and height $(\mathrm{m})$ data were obtained using a digital scale (Tanita, model HS 302) and portable stadiometer (Sanny, model ES 2040), respectively. 
The BMI according to the GA was calculated and the pregnant women were classified as: low weight, adequate weight, overweight and obese, following the criteria proposed by Atalah et al. ${ }^{13}$ The BMI classification criterion proposed by Atalah et al. 13 was developed using data from a prospective study conducted among pregnant Chilean women, which was accepted by the Ministry of Health ${ }^{14}$ to classify the BMI according to the GA among pregnant Brazilian women.

The GA was estimated based on the date of the last menstrual period recorded on pregnant woman's card, later corrected through the ultrasound data recorded in the medical record.

Food consumption was estimated using two 24hour recalls $(24 \mathrm{hR})$ and a food frequency questionnaire (FFQ) obtained by trained nutritionists between the 24th and 39th weeks of gestation.

The two $24 \mathrm{hR}$ were obtained through the multiple-pass technique in three stages (participant report, detailing and review), 15 with the first $24 \mathrm{hR}$ obtained at the time of the interview (in the primary health unit) and the second through telephone contact, with at least seven days between the replications, regardless of the day of the week or season.

The FFQ contains 85 food items and was developed and validated for SUS users in the city of Ribeirão Preto, São Paulo state.16 The FFQ was collected through an interview on the same day as the first $24 \mathrm{hR}$ at the health unit. The FFQ was considered accurate for the estimation of the consumption of foods analyzed in the present study. 16

The nutritional composition of the dietary intake was estimated through means of the NutWin ${ }^{\circledR}$ software (Nutrition Support Program, Version 1.5, São Paulo, 2002), using the Brazilian Table of Chemical Composition of Foods (TACO) ${ }^{17}$ and the table of the United States Department of Agriculture Research Service (USDA). 18

The usual diet was estimated using the Multiple Source Method (MSM).The MSM is a statistica modeling technique program developed by the European Prospective Investigation into Cancer and Nutrition (EPIC). ${ }^{19}$ The method estimates the usual intake of food and nutrients in three steps: 1. Estimation of the probability of intake on a random day; 2. Estimation of usual intake on days of consumption, corrected for variability; 3 . Usual intake of individuals calculated through the product of probability of ingestion on a random day (step 1) by the usual intake on day of consumption (step 2). 20

In addition, the MSM allows data from shortterm dietary measures, such as the $24 \mathrm{hR}$, to be combined with data of the frequency of food consumption from an FFQ. ${ }^{19}$ In the present study, for the estimation of consumption of foods, the $24 \mathrm{hR}$ data corrected for the frequency of consumption reported in the FFQ were used; for the nutrient estimation, all the pregnant women were considered to be consumers, and no adjustment through the FFQ was required. 19

The quality of diet was analyzed through the IQDAG, previously developed to evaluate the diet of pregnant women attended in the SUS of the city of Ribeirão Preto. ${ }^{9}$ The index presents nine components, representing three food groups (portions/1000 kcal) ("Vegetables", "Legumes" and "Fresh Fruits"), five nutrients ("Fiber", "Omega 3", "Calcium", "Folate" and "Iron") and a moderator component (percentage of energy value from ultra-processed foods). A detailed description of the IQDAG scoring criteria is presented in Table 1.9

Information were obtained through a structured questionnaire regarding age (years), education (years of schooling), parity (number of children), practice of physical activity (minutes per week of walking and physical exercises), self-reported skin color (white, brown or other), history of smoking (never smoked, ex-smoker, current smoker) and use of dietary supplements. The economic stratum of women was determined according to the Brazilian Economic Classification Criterion (CCEB), ${ }^{21}$ which defines the strata from A (highest level) to $\mathrm{E}$ (lowest level), based on the possession of items and the level of education of the head of the family.

The basal metabolic rate (BMR) of the pregnant women was calculated using predictive equations and the method of Goldberg et al.20 which was adopted to estimate underreporting of energy intake (EI). An EI:BMR ratio $\leq 1.35$ was considered as underreporting.

The pre-pregnancy weight of all evaluated women was obtained based on data recorded on the obstetric monitoring card of the pregnant woman. Pre-gestational BMI was classified according to the recommendations of the Institute of Medicine. 22

The diagnosis of GDM was performed according to the criteria of the World Health Organization of 2014.23 Fasting blood samples were obtained, as well as within one and two hours after the ingestion of a $75 \mathrm{~g}$ glucose load, with the glucose oxidase test used to determine the plasma glucose. The presence of hypertension during pregnancy was investigated through the self-report of the pregnant woman.

The Kolmogorov-Smirnov test was used to evaluate the normality of the continuous variables. Mean (SD) and median $\left(\mathrm{P}_{25}, \mathrm{P}_{75}\right)$ values were 


\begin{tabular}{|c|c|c|c|}
\hline \multirow[t]{2}{*}{ Component } & \multicolumn{3}{|c|}{ Score } \\
\hline & 0 & 10 & 20 \\
\hline Vegetables/1,000 kcal (in portions) & 0 & $\geq 1.5$ & \\
\hline Legumes $/ 1,000 \mathrm{kcal}$ (in portions) & 0 & $\geq 0.5$ & \\
\hline Fresh fruit/1,000 Kcal (in portions) & 0 & $\geq 1.5$ & \\
\hline Fiber (g) & 0 & $\geq 28.0$ & \\
\hline Omega $3 \mathrm{~b}(\mathrm{mg})$ & 0 & $\geq 1.4$ & \\
\hline Calciumb (mg) & 0 & $\geq 800.0$ & \\
\hline Folateb $(\mu g)$ & 0 & $\geq 520.0$ & \\
\hline Ironb (mg) & 0 & $\geq 22.0$ & \\
\hline Ultra-processed foodsc & $\geq 45$ & - & $\leq 18$ \\
\hline
\end{tabular}

Source: Crivellenti et al.9

a Index proposed to evaluate the quality of the diet of pregnant women; b Estimate from the diet and use of dietary supplements; c percentage of energy from ultra-processed foods.

obtained for the continuous descriptive variables, while the categorical variables were expressed in absolute (n) and relative (\%) frequencies. The ANOVA (continuous variables with normal distribution), Kruskal-Wallis (continuous variables without normal distribution) and chi-square (categorical variables) tests were used to compare the maternal characteristics according to the BMI classification according to the GA.

The ANOVA with Bonferroni correction was used to compare the mean (SD) score of the IQDAG with its components, according to the BMI classification.

Multinomial logistic regression models were used and odds ratio (OR) values and $95 \%$ confidence intervals (CI95\%) were estimated to assess the relationship of the total dietary index score, as well as its components, with overweight and obesity, considering eutrophic women as the reference. The IQDAG score was categorized into tertiles, with the first tertile being adopted as reference.

The adjustment variables of the model considered were: age (years), education (years of schooling), parity (number of children), self-report of skin color (white, brown or others), economic stratum (A, B, C, D and E), history of smoking (never smoked, ex-smoker, current smoker), physical activity (minutes per week of walking and physical exercise), total energy intake ( $\mathrm{kcal} /$ day) and dietary underreporting (yes/no). It should be noted that in the present investigation, the relationship between the components "Fiber", "Omega 3", "Calcium", "Folate" and "Iron" with overweight and obesity was adjusted by total dietary calories using the residual method. These variables were selected based on the theore-tical framework of the influence on food consumption, as well as on the occurrence of excess maternal body weight.

The level of significance was set at $p<0.05$. All analyses were conducted using the SPSS software (SPSS software, Version 17.0, SPSS Inc. Working, Surrey, UK).

\section{Results}

In total, 1,446 women were contacted. Of these, 19 $(1.3 \%)$ did not agree to participate in the study and $642(44.4 \%)$ were excluded after application of the study criteria, giving a total of $785(54.3 \%)$ women. In the present investigation, 31 (3.9\%) women were classified as underweight according to the GA, and therefore were excluded from the statistical analyses. Thus, the sample consisted of 754 pregnant women $(50.4 \%)$.

The mean and the median values of the GA of pregnant women were 27.7 and 27.0 weeks, respectively, ranging from 24 to 39 weeks. Of these women, $70.0 \%$ were between the $24^{\text {th }}$ and $28^{\text {th }}$ week of GA, $21.5 \%$ between the $29^{\text {th }}$ and $32^{\text {nd }}$ week of GA and $8.5 \%$ had gestational age of more than 33 weeks.

Among the 754 participants, $33.4 \%$ were overweight and $25.6 \%$ obese. The age of the women ranged from 20 to 45 years and education ranged from zero to 15 years of schooling. Obese women had a higher mean age, lower levels of schooling, a greater number of children, were mostly classified in economic stratum B, had a greater frequency of obesity in the pre-gestational period, a greater frequency of hypertension during the pregnancy and a greater frequency of diagnosis of GDM, compared 
Sociodemographic characteristics, lifestyle and presence of morbidities of the pregnant women, according to the BMI categories, according to gestational age. Ribeirão Preto, SP, Brazil, 2011-2012. ( $N=754$ )

\begin{tabular}{|c|c|c|c|c|c|c|c|}
\hline & \multicolumn{6}{|c|}{ BMI Classificationa } & \multirow[t]{2}{*}{$p^{b}$} \\
\hline & \multicolumn{2}{|c|}{ Adequate $(n=309)$} & \multicolumn{2}{|c|}{ Overweight $(n=252)$} & \multicolumn{2}{|c|}{ Obesity $(n=193)$} & \\
\hline & \multicolumn{2}{|c|}{$\bar{X} \pm S D$} & \multicolumn{2}{|c|}{$\bar{X} \pm S D$} & \multicolumn{2}{|c|}{$\bar{X} \pm S D$} & \\
\hline \multicolumn{8}{|c|}{ Maternal Characteristics - $\left(\bar{X}_{ \pm} S \mathrm{SD}\right)$} \\
\hline Age (years) & \multicolumn{2}{|c|}{$27.1 \pm 5.4$} & \multicolumn{2}{|c|}{$27.7 \pm 5.4$} & \multicolumn{2}{|c|}{$28.7 \pm 5.7$} & $<0.01$ \\
\hline Education (years) & \multicolumn{2}{|c|}{$9.6 \pm 2.6$} & \multicolumn{2}{|c|}{$9.1 \pm 2.6$} & \multicolumn{2}{|c|}{$9.0 \pm 2.9$} & 0.04 \\
\hline \multirow[t]{2}{*}{ Parity } & \multicolumn{2}{|c|}{$1.1 \pm 1.2$} & \multicolumn{2}{|c|}{$1.2 \pm 1.1$} & \multicolumn{2}{|c|}{$1.4 \pm 1.4$} & 0.01 \\
\hline & \multicolumn{2}{|c|}{$\mathrm{Md}\left(\mathrm{P}_{25}-\mathrm{P}_{75}\right)$} & \multicolumn{2}{|c|}{$\mathrm{Md}\left(\mathrm{P}_{25}-\mathrm{P}_{75}\right)$} & \multicolumn{2}{|c|}{$\mathrm{Md}\left(\mathrm{P}_{25}-\mathrm{P}_{75}\right)$} & \multirow{3}{*}{0.18} \\
\hline \multirow{2}{*}{$\begin{array}{l}\text { Physical activity (min/week) - } \\
M d\left(P_{25}-P_{75}\right)\end{array}$} & \multicolumn{2}{|c|}{$50.0(0.0-150.0)$} & \multicolumn{2}{|c|}{$35.0(0.0-116.3)$} & \multicolumn{2}{|c|}{$50.0(0.0-120.0)$} & \\
\hline & $\mathrm{n}$ & $\%$ & $\mathrm{n}$ & $\%$ & $\mathrm{n}$ & $\%$ & \\
\hline Self reported skin color - $\mathrm{n}(\%)$ & & & & & & & 0.15 \\
\hline White & 143 & 46.3 & 111 & 44.0 & 88 & 44.6 & \\
\hline Brown & 99 & 32.0 & 103 & 40.9 & 67 & 34.7 & \\
\hline Others & 67 & 21.7 & 38 & 15.1 & 148 & 20.7 & \\
\hline Economic stratum & & & & & & & 0.02 \\
\hline A & 0 & 0.0 & 3 & 1.2 & 2 & 1.0 & \\
\hline B & 48 & 15.6 & 42 & 16.7 & 50 & 25.9 & \\
\hline c & 214 & 69.5 & 176 & 69.8 & 119 & 61.7 & \\
\hline D & 46 & 14.9 & 31 & 12.3 & 21 & 10.9 & \\
\hline $\mathrm{E}$ & 1 & 3.0 & 0 & 0.0 & 1 & 0.5 & \\
\hline Smoking history & & & & & & & 0.69 \\
\hline Never smoked & 243 & 78.6 & 198 & 78.6 & 156 & 80.8 & \\
\hline Ex-smoker & 34 & 11.0 & 32 & 12.7 & 24 & 12.4 & \\
\hline Currently smokes & 32 & 10.4 & 22 & 8.7 & 13 & 6.7 & \\
\hline Use of supplements & 215 & 69.6 & 148 & 58.7 & 115 & 59.6 & 0.01 \\
\hline Pre-gestational BMId & & & & & & & $<0.001$ \\
\hline Adequate & 287 & 92.9 & 94 & 37.3 & 9 & 4.7 & \\
\hline Overweight & 21 & 6.8 & 147 & 58.3 & 57 & 29.5 & \\
\hline Obese & 1 & 0.3 & 11 & 4.4 & 127 & 65.8 & \\
\hline Self reported hypertension & 25 & 8.1 & 16 & 6.3 & 33 & 17.1 & $<0.001$ \\
\hline GDMe & 37 & 12.0 & 44 & 17.5 & 54 & 28.0 & $<0.001$ \\
\hline
\end{tabular}

a BMI classification, according to the gestational week, following the criteria of Atalah et al.13 Women classified as underweight $(n=31)$ according to gestational age were excluded from the analyses; b $p$ value according to ANOVA (continuous variables with normal distribution), Kruskal-Wallis (continuous variables without normal distribution) and chisquare (categorical variables) tests; c Minutes per week of walking and exercise; d Classification of pre-gestational BMI according to the Institute of Medicine. 22 Pre-gestational BMI value $\leq 20 \mathrm{~kg} / \mathrm{m}^{2}$ was adopted as inclusion criterion; e GDM Diagnosis, according to World Health Organization criteria. 23

$\mathrm{Md}=$ median; $\mathrm{BMI}=$ body mass index; $\mathrm{GDM}=$ gestational diabetes mellitus.

to eutrophic women. The pregnant women with adequate weight reported a greater frequency of the use of dietary supplements (Table 2). Among the 139 $(18.4 \%)$ women with pre-gestational obesity, 127 (65.8\%) were obese during pregnancy, and among the $225(29.8 \%)$ women that were overweight before pregnancy, $147(58.3 \%)$ were classified as being overweight and $57(29.5 \%)$ as being obese during pregnancy.

The mean score (SD) of the IQDAG was 72.4 
(11.6) points, being significantly higher among the eutrophic pregnant women when compared to the pregnant women with obesity. The women with adequate weight also reported diets with higher fiber content compared to the women that were overweight and obese (Table 3 ).

In adjusted multinomial logistic regression models, it was found that the pregnant women with the highest IQDAG scores (3rd tertile) had a lower chance of being overweight $[\mathrm{OR}=0.56(\mathrm{CI} 95 \%=$ $0.37-0.85)]$ or obese [0.43 (0.26-0.71)], when compared to the pregnant women with lower scores ( 1 st tertile). Women with higher scores ( $3^{\text {rd tertile) }}$ for the "Fiber" [0.51 (0.33-0.78)] and "Iron" [0.62 (0.40-0.96)] components presented a lower chance of being overweight. However, those with the highest scores ( 3 rd tertile) for the percentage of energy from ultra-processed foods were more likely to be overweight [1.72 (1.10-2.94)] or obese [5.24 (2.80 -9.80)], in relation to the pregnant women with lower scores (1 st tertile) (Table 4).

\section{Discussion}

In the present study, there was an inverse association between the IQDAG score and excess maternal body weight, according to the BMI classification according to the GA proposed by Atalah et al. 13 The women categorized in the highest score tertile of the index presented a $44 \%$ lower chance of being classified as overweight and a $57 \%$ lower chance of being classified as obese, compared to the women categorized in the lowest score tertile. In addition, there was an inverse association between the "Fiber" and "Iron" components and being overweight. The women in the highest tertile of the fiber score presented a $49 \%$ lower chance of being overweight, while the women in the highest tertile of the iron score presented a $38 \%$ lower chance. A positive association was, however, observed between the highest tertile of the percentage of energy from ultraprocessed foods and being overweight or obese. The pregnant women with the highest total calorie intake for these products were approximately twice as likely to be overweight and five times as likely to be obese. No previous national epidemiological studies investigating the relationship between dietary indexes and being excessive body weight during pregnancy were found in the literature.

Evidence indicates that dietary indexes constitute an important tool to investigate associations between the quality of the maternal diet and neonatal outcomes, such as birth weight and intrauterine growth. 3 A better quality diet during the pregnancy, evaluated through the Alternative Healthy Eating Index for Pregnancy (AHEI-P), was associated with a lower level of maternal blood glucose and a lower risk of preeclampsia in American women. ${ }^{24}$ It is

Table 3

Mean scores, intake of food groups and nutrients conforming to the Diet Quality Index Adapted for Pregnant Women (IQDAG), in the categories of BMI according to gestational age. Ribeirão Preto, SP, Brazil, 2011-2012. (N = 754)

\begin{tabular}{|c|c|c|c|c|}
\hline & \multicolumn{3}{|c|}{ BMI Classificationa } & \multirow[t]{2}{*}{$p^{b}$} \\
\hline & Adequate $(n=309)$ & Overweight $(n=252)$ & Obesity $(n=193)$ & \\
\hline IQDAG Score & $71.6 \pm 12.1 c$ & $69.9 \pm 11.6$ & $68.3 \pm 11.6$ & $<0.001$ \\
\hline Vegetables $/ 1,000 \mathrm{kcal}$ & $2.4 \pm 1.5$ & $2.4 \pm 1.4$ & $2.2 \pm 1.3$ & 0.28 \\
\hline Legumes/1,000 kcal & $1.7 \pm 1.2$ & $1.5 \pm 0.9$ & $1.5 \pm 0.9$ & 0.09 \\
\hline Fresh fruits/1,000 kcal & $0.9 \pm 0,6$ & $0.8 \pm 0.6$ & $0.8 \pm 0.6$ & 0.43 \\
\hline Fiber $(g)$ & $24.4 \pm 11.0 c$ & $22.3 \pm 7.6 \mathrm{~d}$ & $22.4 \pm 7.4$ & $<0.001$ \\
\hline Omega 3 (mg) & $1.0 \pm 0.4$ & $1.0 \pm 0,3$ & $1.0 \pm 0.4$ & 0.20 \\
\hline Calcium (mg) & $551.5 \pm 244.1$ & $536.4 \pm 235.0$ & $531.8 \pm 246.4$ & 0.62 \\
\hline Folate $(\mu \mathrm{g})$ & $646.2 \pm 1034.7$ & $599.4 \pm 1086.3$ & $477.6 \pm 422.2$ & 0.06 \\
\hline Iron (mg) & $53.1 \pm 40.7$ & $47.0 \pm 41.0$ & $50.0 \pm 43.3$ & 0.23 \\
\hline Ultra-processed foodse & $31.9 \pm 13.4$ & $31.4 \pm 12.3$ & $33.0 \pm 13.2$ & 0.43 \\
\hline
\end{tabular}

a Classification of BMI according to gestational week.13 Women classified as low weight $(n=31)$ according to gestational age were excluded from the analyses; bp value ANOVA; c Difference in the mean of the women with adequate BMI, compared to the women with obesity, after Bonferroni test; d Difference in the mean of the women with adequate BMI, compared to the women who were overweight, after Bonferroni test; $\mathrm{BMI}=$ body mass index; e percentage of energy from ultra-processed foods. 
Association of the Diet Quality Index Adapted for Pregnant Women (IQDAG), and its components, with overweight and obesity. Ribeirão Preto, SP, 2011-2012. $(\mathrm{N}=754)^{\mathrm{a}}$

\begin{tabular}{|c|c|c|c|c|c|c|}
\hline & \multicolumn{3}{|c|}{ Overweight OR (CI95\%)b } & \multicolumn{2}{|c|}{ Obesity OR (CI95\%)b } & \multirow[b]{2}{*}{$\begin{array}{l}\text { 3rd Tertile } \\
\quad(n=74)\end{array}$} \\
\hline & $\begin{array}{l}\text { 1st Tertile } \\
(n=77)\end{array}$ & $\begin{array}{l}\text { 2nd Tertile } \\
(n=80)\end{array}$ & $\begin{array}{l}\text { 3rd Tertile } \\
(n=95)\end{array}$ & $\begin{array}{l}\text { 1st Tertile } \\
(n=47)\end{array}$ & $\begin{array}{l}\text { 2nd Tertile } \\
(n=72)\end{array}$ & \\
\hline IQDAG & Ref & $0.78(0.51-1.19)$ & $0.56(0.37-0.85)$ & Ref & $0.92(0.57-1.49)$ & $0.43(0.26-0.71)$ \\
\hline Vegetables $/ 1,000 \mathrm{kcal}$ & Ref & $1.23(0.81-1.89)$ & $1.03(0.67-1.58)$ & Ref & $0.66(0.40-1.07)$ & $0.72(0.45-1.17)$ \\
\hline Legumes/1,000 kcal & Ref & $0.81(0.53-1.24)$ & $0.75(0.49-1.15)$ & Ref & $0.55(0.34-0.90)$ & $0.74(0.46-1.21)$ \\
\hline Fresh fruits $/ 1,000 \mathrm{kcal}$ & Ref & $0.93(0.60-1.42)$ & $0.98(0.64-1.49)$ & Ref & $0.90(0.55-1.33)$ & $0.81(0.50-1.33)$ \\
\hline Fiberc (g) & Ref & $0.86(0.56-1.30)$ & $0.51(0.33-0.78)$ & Ref & $0.76(0.46-1.25)$ & $0.79(0.49-1.29)$ \\
\hline Omega 3c (mg) & Ref & $0.98(0.64-1.47)$ & $0.89(0.58-1.36)$ & Ref & $0.94(0.57-1.54)$ & $1.16(0.71-1.88)$ \\
\hline Calciumc (mg) & Ref & $1.11(0.73-1.68)$ & $1.12(0.73-1.71)$ & Ref & $1.21(0.75-1.97)$ & $1.22(0.74-2.00)$ \\
\hline Folatec $(\mu \mathrm{g})$ & Ref & $0.85(0.56-1.30)$ & $0.98(0.65-1.53)$ & Ref & $0.63(0.39-1.06)$ & $0.75(0.46-1.22)$ \\
\hline Ironc (mg) & Ref & $0.57(0.37-0.87)$ & $0.62(0.40-0.96)$ & Ref & $0.72(0.43-1.20)$ & $0.74(0.45-1.21)$ \\
\hline Ultra-processed foodsd & Ref & $2.08(1.32-3.27)$ & $1.72(1.10-2.94)$ & Ref & $3.55(2.08-6.06)$ & $5.24(2.80-9.80)$ \\
\hline
\end{tabular}

a 31 women classified as underweight according to gestational age were excluded from the analysis;

b Multinomial logistic regression models, considering the first tertile of consumption and eutrophic women as the reference, adjusted for: age (years), education (years of schooling), parity (number of children), physical activity (minutes per week of walking and physical exercises), self-report skin color (white, brown or others), economic stratum (A or B, C, D or E), smoking history (never smoked, ex-smoker, current smoker) total energy ingestion (kcal) and dietary underreporting (yes/no);

c Adjusted by total dietary calories, using the residual method;

d percentage of energy from ultra-processed foods;

$\mathrm{OR}=$ odds ratio; Ref = reference value.

emphasized that due to differences between the indexes and the methods of dietary evaluation used, the comparison of results, in particular those of dietary components alone, becomes difficult and limited.

The inverse association between the IQDAG and excess body weight during pregnancy is in agreement with the findings of a study conducted in Greece, which used the HEI-2005 to assess diet quality. In this study, a higher index score was inversely associated with being overweight and obese during pregnancy. ${ }^{8}$ Similar to the IQDAG, the HEI-2005 considers the consumption of fruits, vegetables and legumes among its components.

Several factors may explain the inverse relationship between fiber intake and being overweight, since diets with fibers have low energy density, high nutritional value and high satiating power. 25 Regarding the inverse association between iron intake and being overweight verified in the present study, it is emphasized that eutrophic pregnant women were more likely to use dietary supplements, which may partially explain the findings, since there is no biological plausibility for this association.

The IQDAG was the first national index to incorporate one of the main recommendations of the Food Guide for the Brazilian Population: avoiding the consumption of ultra-processed foods. 10 It is believed that the inclusion of ultra-processed foods as a moderating component of the index is relevant in the context of public health, as their excessive consumption is directly associated with the occurrence of obesity.11 Diets rich in ultra-processed foods are nutritionally unbalanced, since they have a higher content of added sugars, total fats, saturated fats, trans fats, cholesterol, sodium and lower content of fiber, protein and various micronutrients.

Evidence suggests that the high consumption of ultra-processed foods during pregnancy is a predictor of greater maternal weight gain and neonatal adiposity. 26 In a prospective study conducted among pregnant women during the 32nd and $37^{\text {th }}$ weeks of gestation, it was observed that each increase of $1 \%$ in energy intake from ultraprocessed foods corresponded to a $1.33 \mathrm{~kg}$ increase in gestational weight gain $(p=0.016)$ and a $0.62 \%$ increase in the total body adiposity of the newborn $(p=0.037) .26$

In the present study, there was no difference between the mean of percentage of energy from ultra-processed foods among the women with adequate BMI, those that were overweight and those with obesity during the pregnancy. This can be partly explained by the high percentage of overweight and obese pregnant women that underreported the diet ( $48 \%$ and $72 \%$, respectively), when compared to the 
pregnant women with adequate BMI (33\%) (data not presented). This fact may explain the strong association between this dietary component and the outcomes in the adjusted models (including dietary underreporting), even without a mean difference in consumption.

Consistent with previous studies, it was observed that the women with obesity during pregnancy presented greater age, higher parity, higher frequency of being classified in intermediate level economic strata and lower levels of education. ${ }^{27}$

The present study was a pioneer in Brazil due to investigating the relationship between the quality of the diet during pregnancy, through a dietary index, and excess maternal body weight. Data were collected by trained nutritionists and data from two $24 \mathrm{hR}$ and one FFQ were used to estimate the usual diet, adjusted by MSM, ensuring greater data reliability. Food consumption information was obtained simultaneously with the anthropometric evaluation and the screening for GDM, so the women had not yet altered their dietary intake as a result of these diagnoses. However, some of the women classified as being overweight during pregnancy already presented this disorder in the pre-gestational period and the possibility of reverse causality cannot be ruled out. The main limitation of the study was the transversal design, making it impossible to identify a temporal relationship. Women with pre-gestational $\mathrm{BMI} \geq 20 \mathrm{~kg} / \mathrm{m}^{2}$ were included in the study, and few presented low weight during the pregnancy, which may limit the extrapolation of the data. In addition, due to the lack of information about weight gain in the first trimester of the pregnancy, it was not possible to investigate the relationship between diet quality and gestational weight gain. The adoption of the criteria proposed by Atalah et al. ${ }^{13}$ for the classification of BMI according to GA in Brazilian pregnant women is controversial, 28 however, we do not know of another classification available for this population. In addition, this criterion is recommended by the Ministry of Health for evaluating pregnant women in the country. ${ }^{14}$ Another limitation of the study refers to the use of logistic regression in cross-sectional studies with high prevalence

\section{References}

1. Poston L, Caleyachetty R, Cnattingius S, Corvalán C, Uauy R, Herring S, Gillman MW. Preconceptional and maternal obesity: epidemiology and health consequences. Lancet Diabetes Endocrinol. 2016; 4 (12): 1025-36.

2. Godfrey KM, Reynolds RM, Prescott SL, Nyirenda M, Jaddoe VW, Eriksson JG, Broekman BF. Influence of maternal obesity on the long-term health of offspring. outcomes, which has been criticized by some authors. However, this measure of association was adopted because it is recommended for crosssectional studies that aim to investigate the effect of an exploratory variable on the occurrence of a health outcome. ${ }^{29}$ Dietary underreporting was verified in $47 \%$ of the pregnant women, estimated using the formula of Goldberg et al. ${ }^{20}$ (cut-off point $\leq 1.35$ ). This high proportion of diet underreporting among the study participants corroborates a previous study conducted among pregnant Irish women, in which the underreporting of energy intake was $42 \%$, even using a cut-off point $\leq 1.2 .30$ It should be emphasized that the Goldberg method may not be the best approach to estimate dietary underreporting during pregnancy, since it does not consider the physical activity of individuals and assumes the maintenance of the body weight.

The data suggest that nutritional interventions are necessary among pregnant women to promote the overall quality of the diet, with an emphasis on promoting the consumption of natural and minimally processed foods and foods that are rich in nutrients important in pregnancy. Prospective studies and randomized clinical trials are recommended to confirm the hypothesis of the present study.

Poorer quality diets were observed among those women that were overweight and obese in the gestational period. Nutritional interventions to promote higher quality diets among pregnant women are necessary.

\section{Author's Contribuition}

Crivellenti LC, Zuccolotto DCC, Sartorelli DS contributed in the conception and planning of this study. Data collection was performed by Crivellenti LC and Zuccolotto DCC, and data analysis and interpretation were carried out by Sartorelli DS and Crivellenti LC. The manuscript was elaborated and revised by Crivellenti LC. All of the authors approved the final version of the manuscript and took public responsibility on the article's content.

Lancet Diabetes Endocrinol. 2017; 5 (1): 53-64.

3. Martin JC, Zhou SJ, Flynn AC, Malek L, Greco R, Moran L. The Assessment of Diet Quality and Its Effects on Health Outcomes Pre-pregnancy and during Pregnancy. Semin Reprod Med. 2016; 34 (2): 83-92.

4. Tobias D, Bao W. Diet during Pregnancy and Gestational Weight Gain. CurrNutr Rep. 2014; 3 (3): 289-97. 
5. Kourlaba G, Panagiotakos DB. Dietary quality indices and human health: a review. Maturitas. 2009; 62 (1): 1-8.

6. Mariscal-Arcas, M, Rivas A, Monteagudo C, Granada A, Cerrillo I, Olea-Serrano F. Proposal of a Mediterranean diet index for pregnant women. Br J Nutr. 2009; 102 (5): 744 49.

7. Han CY, Colega M, Quah EPL, Chan YH, Godfrey KM, Kwek K, Saw SM, Gluckman PD, Chong YS, Chong MFF. A healthy eating index to measure diet quality in pregnant women in Singapore: a cross-sectional study. BMC Nutrition. 2015; 1 (39): 1-11

8. Tsigga M, Filis V, Hatzopoulou K, Kotzamanidis C, Grammatikopoulou MG. Healthy Eating Index during pregnancy according to pre-gravid and gravid weight status Public Health Nutr. 2011; 14 (2): 290-6.

9. Crivellenti LC, Zuccolotto DCC, Sartorelli DS Desenvolvimento de um Índice de Qualidade da Dieta Adaptado para Gestantes. Rev Saúde Pública. 2018; 52 (59): 1-11.

10. Brasil. Ministério da Saúde. Secretaria de Atenção à Saúde. Departamento de Atenção Básica. Guia alimentar para população brasileira. 2 ed. Brasília, DF; 2014. [acesso em 4 jun 2018]. Disponível em: http://bvsms.saude.gov.br/bvs/ publicacoes/guia_alimentar_populacao_brasileira_2ed.pdf.

11. Monteiro CA, Cannon G, Moubarac JC, Levy RB, Louzada MLC, Jaime PC. The UN Decade of Nutrition, the NOVA food classification and the trouble with ultra-processing. Public Health Nutr. 2018; 21 (1): 5-17.

12. Barbieiri P, Nunes JC, Torres AG, Nishimura RY, Zuccolotto DC, Crivellenti LC, Franco LJ, Sartorelli DS. Indices of dietary fat quality during mid pregnancy is associated with gestational diabetes. Nutrition. 2016; 32 (6) 656-61.

13. Atalah E, Castillo C, Castro R, Aldea A. Propuesta de um nuevo estandar de evaluación nutricional em embarazadas. Rev Med Chile. 1997; 125 (12): 1429-36.

14. Brasil. Ministério da Saúde. Secretaria de Atenção à Saúde. Departamento de Atenção Básica. Atenção ao pré-natal de baixo risco. Série A. Normas e Manuais Técnicos. Cadernos de Atenção Básica 32. Brasília, DF; 2012. [acesso em 8 out 2018]. Disponível em: http://bvsms.saude.gov.br/bvs/publicacoes/cadernos_atencao_basica_32_prenatal.pdf.

15. Johnson RK, Soultanakis RP, Matthews DE. Literacy and body fatness are associated with underreporting of energy intake in US low-income women using the multiple-pass 24-hour recall: a doubly labeled water study. J Am Diet Assoc. 1998; 98 (10): 1136-40.

16. Barbieri P, Crivellenti LC, Nishimura RY, Sartorelli DS Validation of a food frequency questionnaire to assess food group intake by pregnant women. J Hum Nutr Diet. 2015; 28 (Suppl. 1): 38-44.

17. Universidade Estadual de Campinas, Núcleo de Estudos e Pesquisas em Alimentação. Tabela brasileira de composição de alimentos - TACO. 2 ed. Campinas: NEPA; 2006. [acesso em 4 jun 2018]. Disponível em: http://www.crn1. org.br/wpcontent/uploads/2015/04/taco.pdf?x53725

Received on June 21, 2018

Final version presented on November 13, 2018

Approved on December 28, 2018
18. USDA National Nutrient Database for Standard Reference. Beltsville: U.S. Departament of Agriculture, Agricultural Research Service Research; 2001. [acesso em 4 jun 2018].Disponível em: https:// www.ars.usda.gov/northeastarea/beltsville-md/beltsvillehuman-nutrition-researchcenter/ nutrient-data-laboratory/docs/ sr14-home-page.

19. Haubrock J, Nöthlings U, Volatier JL, Dekkers A, Ocké M, Harttig U, Illner AK, Knüppel S, Andersen LF, Boeing H. European Food Consumption Validation Consortium. Estimating usual food intake distributions by using the multiple source method in the EPIC-Potsdam Calibration Study. J Nutr. 2011; 141 (5): 914-20.

20. Goldberg GR, Black AE, Jebb SA, Livingstone MB, Cole TJ, Prentice AM. Critical evaluation of energy intake data using fundamental principles of energy intake physiology: 1. derivation of cut-off limits to identify under-recording. Eur J Clin Nutr. 1991; 45 (12): 569-81.

21. Associação Brasileira de Empresa de Pesquisa. Dados com base no levantamento socioeconômico 2012 - IBOPE. São Paulo; ABEP; 2012. [acesso em 4 jun 2018]. Disponível em: http://www.abep.org/criterio-brasil

22. Institute of Medicine, National Research Council (US) Committee to Reexamine IOM Pregnancy Weight Guidelines; Rasmussen KM, Yaktine AL, editors. Weight gain during pregnancy: reexamining the guidelines. Washington, DC: The National Academies Press; 2009.

23. WHO. Diagnostic criteria and classification of hyperglycemia first detected in pregnancy: a World Health Organization Guideline. Diabetes Res Clin Pract. 2014; 103: 341-63.

24. Rifas-Shiman SL, Rich-Edwards JW, Kleinman KP, Oken E, Gillman MW. Dietary quality during pregnancy varies by maternal characteristics in Project Viva: a US cohort. J Am Diet Assoc. 2009; 109 (6): 1004-11.

25. Mozaffarian D, Hao T, Rimm EB, Willett WC, Hu FB. Changes in diet and lifestyle and long-term weight gain in women and men. N Engl J Med. 2011; 364 (25): 2392-404.

26. Rohatgi KW, Tinius RA, Cade WT, Steele EM, Cahill AG, Parra DC. Relationships between consumption of ultraprocessed foods, gestational weight gain and neonatal outcomes in a sample of US pregnant women. Peer J. 2017; 5: e4091.

27. Ferreira RAB, Benicio MHDA. Obesidade em mulheres brasileiras: associação com paridade e nível socioeconômico. Rev Panam Salud Pública. 2015; 37 (4/5): $337-42$.

28. Kac G, Nucci LB, Spyrides MH, Duncan BB, Schmidt MI. Evaluation of the ability of a Latin American gestational weight curve to predict adverse pregnancy outcomes. Int $\mathrm{J}$ Gynaecol Obstet. 2009; 106 (3): 223-6.

29. Reichenheim ME, Coutinho ESF. Measures and models for causal inference in crosssectional studies: arguments for the appropriateness of the prevalence odds ratio and related logistic regression. BMC Med Res Methodol. 2010; 10 (66): 1-12.

30. McGowan CA, McAuliffe FM. Maternal nutrient intakes and levels of energy underreporting during early pregnancy. Eur J Clin Nutr. 2012; 66 (8): 906-13. 